\title{
BEM-ESTAR SOCIAL BRASILEIRO NO SÉCULO XXI: DA INCLUSÃO AO RETORNO DA EXCLUSÃO SOCIAL
}

\author{
Jorge Abrahấo de Castro $^{1}$ id
}

\begin{abstract}
RESUMO: No processo de desenvolvimento de um país, ocorrem relaçôes sociais de produção que resultam em determinadas condiçóes de vida para suas populaçóes que, em síntese, pode significar maior ou menor bem-estar social. Este trabalho reconstrói as condiçóes de vida da população brasileira no início do século XXI para captar a evolução do seu bem-estar social. Constataram-se dois períodos distintos: um inicial, de inclusão social e de maior bem-estar social, e o seguinte, de retorno da exclusão social e de reduçáo do bem-estar social. O retorno da exclusão mostra as fragilidades do processo de inclusão social do início do século, que apenas perturbou o longo e duradouro padrão de exclusão e injustiça social vigente no país.
\end{abstract}

Palavras-chave: Bem-estar social. Condiçóes de vida. Inclusão social. Exclusão social.

\section{BRAZILIAN SOCIAL WELL-BEING IN THE 21ST CENTURY: FROM INCLUSION TO THE RETURN OF SOCIAL EXCLUSION}

ABSTRACT: In the process of developing a country there are social relations of production that result in certain living conditions for its populations which, in short, can mean greater or lesser social well-being. This work reconstructs the living conditions of the Brazilian population, at the beginning of the 21 st century, to capture the evolution of their social well-being. There were two distinct periods, an initial one of social inclusion and of greater social well-being and the following one of reduction of social exclusion and reduction of social well-being. The return of exclusion shows the weaknesses of the social inclusion process, of the beginning of the century, that only disturbed the country's long lasting pattern of social exclusion and injustice.

Keywords: Social well-being. Living conditions. Social inclusion. Social exclusion.

\footnotetext{
${ }^{1}$ Universidade de Brasília - Brasilia (DF), Brasil. E-mail: jorge.abrahao57@gmail.com
} DOI: 10.1590/ES0101-73302019222141 


\title{
BIENESTAR SOCIAL BRASILEÑO EN EL SIGLO XXI: DE LA INCLUSIÓN AL REGRESO A LA EXCLUSIÓN SOCIAL
}

\begin{abstract}
RESUMEN: En el proceso de desarrollo de un país existen relaciones sociales de producción que resultan en ciertas condiciones de vida para sus poblaciones que, en resumen, pueden significar un mayor o menor bienestar social. Este documento reconstruye las condiciones de vida de la población brasileńa a principios del siglo XXI para capturar la evolución de su bienestar social. Se encontraron dos períodos distintos, el primero de inclusión social y de mayor bienestar social y el siguiente de retorno de la exclusión social y reducción del bienestar social. El regreso a la exclusión muestra las debilidades del proceso social temprano de inclusión social, que solo perturbó el patrón largo y duradero de exclusión social e injusticia en el país.
\end{abstract}

Palabras clave: Bienestar social. Condiciones de vida. Inclusión social. Exclusión social.

\section{Introdução}

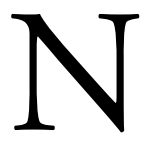

o processo de desenvolvimento dos países, as relaçóes sociais de produção determinam condiçóes de vida - relacionadas às necessidades sociais básicas da população - cuja síntese expressa o bem-estar social prevalecente nos países. Adotando essa perspectiva, este trabalho busca reconstruir a evolução das condiçóes de vida da população brasileira no início do século XXI, para captar as mudanças no bem-estar social de sua populaçáo no período. Importante considerar que o pano de fundo dessas mudanças se relaciona diretamente com a característica do subdesenvolvimento do país e a ordem neoliberal vigente.

A ideia de condiçóes de vida será operacionalizada mediante a utilização de um conjunto de dimensóes ligadas a fatores econômicos e sociais da população. A quantidade e a qualidade analítica das dimensões são determinadas pela disponibilidade de dados e informaçóes. Apesar de importantes, alguns recortes analíticos possíveis, tais como região, gênero, localidade, raça/cor, não foram tratados de forma específica, mas apenas utilizados em algumas situaçóes.

Utiliza-se, também, o binômio inclusão/exclusão como critério para caracterizar períodos históricos de aceitação/negação, principalmente pela política pública, ao atendimento de necessidades de indivíduos e grupos sociais, relativas ao acesso à renda e usufruto de bens e serviços sociais.

Dessa escolha analítica derivou a especificação de oito dimensôes: trabalho e renda, previdência social, pobreza, desigualdade de renda, saúde, educação, 
saneamento básico e habitação, segurança pública e violência. Para cada dimensão, foram utilizados dados, indicadores e informaçôes das políticas públicas em determinados anos que demarcam os períodos de governo no âmbito federal. A análise centra-se no século XXI, especificamente em dois períodos: 2003-2014, anos dos governos Lula e Dilma; e 2015-2018, anos do breve segundo governo Dilma e o de Temer, que foi produto do golpe político-parlamentar.

O trabalho está dividido em três seçôes. Na primeira, apresentam-se os dados, as informações e a análise das condições de vida dos anos de 2003-2014, período de crescimento econômico e de ampliação das políticas sociais. A segunda seção segue a mesma metodologia para anos 2015-2018, período de austeridade fiscal, baixo crescimento, golpe político-parlamentar e de restriçóes às políticas sociais. Por último, são feitas consideraçôes gerais a respeito dos resultados em termos de bem-estar social nesse início de século.

\section{Bem-estar social de 2003-2014: período de inclusão social}

A configuração do bem-estar social desse período será realizada mediante análise dos indicadores sociais de cada uma das dimensóes das condiçóes de vida, que são apresentadas na Tabela 1. Para complementar a análise, vai-se utilizar dados e informaçôes das políticas sociais e dos gastos públicos, que são exibidos na Tabela 2. A análise ficou centrada no período 2003-2014, governos Lula e Dilma. Já a apresentação dos dados para 1990 servem para percepção da evolução mais longa do bem-estar social brasileiro.

$\mathrm{Na}$ dimensão do trabalho e renda, os indicadores mostram melhorias no mercado de trabalho e expansão da renda entre 2002 e 2014. Na Tabela 1, observa-se que o rendimento mensal médio de todos os trabalhos para pessoas de 15 anos ou mais de idade, que tinha caído na década de 1990, passou a crescer entre 2002 e 2014 , com um crescimento real de $39 \%$. O desemprego, que vinha se elevando ao fim da década de 1990 e início do século XXI, tem desde 2005 uma tendência à queda e atinge $7,5 \%$ em 2014, seu menor valor. Nesse período, de acordo com dados da Tabela 2, também foram criados mais de 20 milhóes de empregos formais. Com isso, a taxa de informalidade, que sempre foi elevada, experimentou um processo de redução, saindo de 58,3 para $46,4 \%$ entre 2002 e 2014. As razões que explicam essas melhorias estáo na dinâmica do mercado de trabalho e nas políticas públicas que aproveitaram o crescimento econômico conjuntural. Outro elemento importante foi a política de valorização real do salário mínimo (SM) - que teve crescimento real de $70 \%$ - e o conjunto dos benefícios de transferência de renda da política social (ver Tabela 2).

$\mathrm{Na}$ dimensão da previdência social, ocorreu maior inclusão no sistema previdenciário e crescimento da renda das transferências previdenciárias. A Tabela 1 mostra que a cobertura previdenciária com respeito à populaçáo ativa, entre 16 e 59 


\section{Tabela 1}

Condições de vida: dimensões e painel de indicadores selecionados: 1990/2002/2014.

\begin{tabular}{|c|c|c|c|c|}
\hline \multirow{2}{*}{ Dimensóes } & \multirow{2}{*}{ Indicadores } & \multicolumn{3}{|c|}{ Resultados/valores } \\
\hline & & 1990 & 2002 & 2014 \\
\hline \multirow{5}{*}{$\begin{array}{l}\text { Trabalho } \\
\text { e renda }\end{array}$} & Taxa de desemprego na população > 10 anos (\%) & $\begin{array}{c}7,1 \\
(1992)\end{array}$ & 9,8 & 7,5 \\
\hline & Renda domiciliar per capita real, out. 2014 (R\$ 1) & 641,6 & 716,3 & $1.152,2$ \\
\hline & $\begin{array}{l}\text { Empregados com vínculo formal de emprego } \\
\text { (milhôes) }\end{array}$ & $\begin{array}{c}23,8 \\
(1995)\end{array}$ & 28,7 & 49.6 \\
\hline & Grau de informalidade (\%) (GII-Ipeadata) & $\begin{array}{c}59,7 \\
(1993)\end{array}$ & 58,3 & 46,4 \\
\hline & $\begin{array}{l}\text { Rendimento médios reais em todas fontes }(\mathrm{R} \$ 1 \text { de } \\
\text { out. 2014) }\end{array}$ & $\begin{array}{c}923 \\
(1992)\end{array}$ & 1.102 & 1.737 \\
\hline \multirow{4}{*}{$\begin{array}{l}\text { Previdência } \\
\text { social }\end{array}$} & População ocupada 16 a 59 anos protegida (\%) & 67,0 & 61,7 & 72,5 \\
\hline & $\begin{array}{l}\text { População > } 60 \text { anos protegida, recebe ou } \\
\text { contribui }(\%)\end{array}$ & 74,1 & 81,5 & 81,7 \\
\hline & $\begin{array}{l}\text { População com renda < 1/2 SM per capita sem/ } \\
\text { previdência. }(\%)\end{array}$ & $\begin{array}{c}67,8 \\
(1992)\end{array}$ & 60,2 & 37,6 \\
\hline & $\begin{array}{l}\text { População com renda < 1/2 SM per capita com/ } \\
\text { previdência. }(\%)\end{array}$ & $\begin{array}{c}61,8 \\
(1992)\end{array}$ & 50,6 & 24,2 \\
\hline \multirow{4}{*}{ Pobreza } & População com renda < 1/4 SM per capita (\%) & 33,2 & 25,7 & 8,1 \\
\hline & Populaçáo vivendo com menos de R\$ 233 (FGV) (\%) & $\begin{array}{c}34,3 \\
(1992)\end{array}$ & 26,7 & 8,4 \\
\hline & $\begin{array}{l}\text { População pobreza - linha das necessidades } \\
\text { calóricas, IPEA (\%) }\end{array}$ & 41,9 & 34,4 & 13,3 \\
\hline & $\begin{array}{l}\text { População extrema pobreza - linha das } \\
\text { necessidades calóricas, IPEA (\%) }\end{array}$ & 20,0 & 14,0 & 4,2 \\
\hline \multirow{6}{*}{$\begin{array}{l}\text { Desigualdade } \\
\text { de renda }\end{array}$} & Desigualdade de renda - Gini & 0,613 & 0,589 & 0,518 \\
\hline & Participação do 1\% mais rico na renda (\%) & 12,2 & 13,4 & 11,3 \\
\hline & Participação do $10 \%$ mais rico na renda (\%) & 48,8 & 47,0 & 40,9 \\
\hline & Participação do 40\% mais pobre na renda (\%) & 7,4 & 8,5 & 11,4 \\
\hline & $\begin{array}{l}\text { Razão } 10 / 40 \text { (renda média do } 10 \%+\text { ricos } / 40 \%+ \\
\text { pobres) }\end{array}$ & 26,5 & 22,2 & 14,4 \\
\hline & $\begin{array}{l}\text { Proporção dos mais pobres com renda igual ao dos } \\
1 \% \text { mais rico }\end{array}$ & 30,5 & 25,2 & 15,4 \\
\hline \multirow{4}{*}{ Saúde } & $\begin{array}{l}\text { Taxa de Mortalidade Infantil (por mil Nascidos } \\
\text { Vivos) }\end{array}$ & 47,1 & 23,4 & 12,4 \\
\hline & $\begin{array}{l}\text { Taxa de Mortalidade na Infância (por mil } \\
\text { Nascidos Vivos) }\end{array}$ & 53,7 & 27,2 & 14,9 \\
\hline & Razão de mortalidade materna (por 100 mil) & 143,2 & 76,0 & 58,4 \\
\hline & Esperança de Vida ao Nascer (anos) & $\begin{array}{c}66,9 \\
(1991)\end{array}$ & 70.7 & 75,2 \\
\hline
\end{tabular}


Tabela 1

Continuação.

\begin{tabular}{|c|c|c|c|c|}
\hline \multirow{2}{*}{ Dimensóes } & \multirow{2}{*}{ Indicadores } & \multicolumn{3}{|c|}{ Resultados/valores } \\
\hline & & 1990 & 2002 & 2014 \\
\hline \multirow{8}{*}{ Educação } & Taxa de frequência à escola (0 a 3 anos) (\%) & nd & 11,7 & 24,6 \\
\hline & Taxa de analfabetismo (15 anos ou mais) (\%) & $\begin{array}{c}17,2 \\
(1992)\end{array}$ & 11,9 & 8,3 \\
\hline & $\begin{array}{l}\text { Número médio de anos de estudos (população > } \\
25 \text { anos) (anos) }\end{array}$ & 4,8 & 6,1 & 7,7 \\
\hline & $\begin{array}{l}\text { População > } 16 \text { anos com o ensino fundamental } \\
\text { concluído }(\%)\end{array}$ & nd & $\begin{array}{c}58,2 \\
(2004)\end{array}$ & 74,3 \\
\hline & $\begin{array}{l}\text { Taxa liquida de frequência ao ensino médio } \\
\text { ajustada (\%) }\end{array}$ & nd & $\begin{array}{c}51,1 \\
(2004)\end{array}$ & 65,7 \\
\hline & Notas no IDEB - EF_inicial & nd & $\begin{array}{c}3,8 \\
(2005)\end{array}$ & $\begin{array}{c}5,2 \\
(2013)\end{array}$ \\
\hline & Notas no IDEB - EF_final & nd & $\begin{array}{c}3,5 \\
(2005)\end{array}$ & $\begin{array}{c}4,2 \\
(2013)\end{array}$ \\
\hline & Notas no IDEB - EM & nd & $\begin{array}{c}3,4 \\
(2005)\end{array}$ & $\begin{array}{c}3,7 \\
(2013)\end{array}$ \\
\hline \multirow{6}{*}{$\begin{array}{l}\text { Saneamento } \\
\text { básico e } \\
\text { habitaçấo }\end{array}$} & $\begin{array}{l}\text { Domicílios sem abastecimento adequada de água } \\
\text { potável }(\%)\end{array}$ & nd & 15,7 & 9,1 \\
\hline & Domicílios sem esgotamento sanitário adequado (\%) & nd & 39,1 & 32,4 \\
\hline & Domicílios sem coleta de lixo adequado (\%) & nd & 15,0 & 10,2 \\
\hline & Domicílios com adensamento excessivo (\%) & nd & 6,7 & 3,2 \\
\hline & Domicílios adequados para moradia (\%) & nd & $\begin{array}{c}51,7 \\
(2004) \\
\end{array}$ & 62,1 \\
\hline & $\begin{array}{l}\text { Déficit habitacional relativo aos domicílios } \\
\text { particulares }(\%)\end{array}$ & nd & $\begin{array}{c}10,4 \\
(2007)\end{array}$ & 9,1 \\
\hline \multirow{6}{*}{$\begin{array}{l}\text { Segurança } \\
\text { pública e } \\
\text { violência }\end{array}$} & Taxa de homicídio (por 100 mil) & 22,2 & 28,5 & 29,3 \\
\hline & Taxa de homicídio por armas de fogo (por $100 \mathrm{mil}$ ) & 11,5 & 19,5 & 21,1 \\
\hline & $\begin{array}{l}\text { Taxa de homicídio na populaçáa } 15 \text { a } 29 \text { anos, } \\
\text { homens (por } 100 \text { mil) }\end{array}$ & 77,5 & 105,4 & 108,1 \\
\hline & Crimes Violentos Intencionais (CVLI) (mil) & nd & $\begin{array}{c}44,6 \\
(2007)\end{array}$ & 57,1 \\
\hline & Número Absoluto de estupros registrados (mil) & nd & $\begin{array}{c}33,9 \\
(2009)\end{array}$ & 50,4 \\
\hline & Roubo e furto de veículos (mil) & nd & $\begin{array}{l}117,7 \\
(2007)\end{array}$ & 242,7 \\
\hline
\end{tabular}

FGV: Fundação Getulio Vargas; IPEA: Instituto de Pesquisa Econômica Aplicada; IDEB:

Índice de Desenvolvimento da Educação Básica; nd: nada a declarar.

Fonte: Ipea (Diretoria de Estudos e Politicas Sociais e Ipeadata) (2018), IDB/RIPSA (Indicadores e dados básicos/Rede interagencial de informaçōes para saúde) (RIPSA, 2013), Fundação João Pinheiro (2018), FGV (2018), Instituto Nacional de Estudos e Pesquisas Educacionais Anisio Teixeira (2018),

Ministério da Justiça (anuário fórum) (2018), Ministério da Economia (informe previdenciários) (BRASIL, 2018). 
Tabela 2

Dimensões e gastos: benefícios básicos da intervenção da política pública brasileira e gastos públicos: 2002/2014/2015/2016/2017.

\begin{tabular}{|c|c|c|c|c|c|c|}
\hline \multirow{2}{*}{$\begin{array}{l}\text { Dimensóes } \\
\text { e gastos }\end{array}$} & \multirow{2}{*}{ Benefícios e outros } & \multicolumn{5}{|c|}{ Valores } \\
\hline & & 2002 & 2014 & 2015 & 2016 & 2017 \\
\hline \multirow{4}{*}{$\begin{array}{l}\text { Trabalho e } \\
\text { renda }\end{array}$} & $\begin{array}{l}\text { Beneficiários do Seguro Desemprego } \\
\text { (milhóes) }\end{array}$ & 4,8 & 9,3 & 8,4 & - & - \\
\hline & $\begin{array}{l}\text { Beneficiários do Abono Salarial } \\
\text { (milhóes) }\end{array}$ & 7,8 & 22,1 & 21,5 & - & - \\
\hline & Contratos pelo Pronaf & 0,9 & \multicolumn{2}{|c|}{1,5} & - & - \\
\hline & $\begin{array}{l}\text { Salário Mínimo médio anual - ICV estrato } \\
\text { inferior (valor em } \mathrm{R} \$ 1,0 \text { ) }\end{array}$ & 536,8 & 944,4 & 927,7 & 946,4 & 982,3 \\
\hline \multirow{7}{*}{$\begin{array}{l}\text { Previdência } \\
\text { Social }\end{array}$} & $\begin{array}{l}\text { Beneficiários do Regime Geral } \\
\text { Previdência Social (RGPS), Total } \\
\text { (milhôes) }\end{array}$ & 18,9 & 28,0 & 28,4 & 29,3 & 29,8 \\
\hline & Beneficiários do RGPS, urbano (milhöes) & 12,3 & 18,7 & 19,0 & 19,8 & 20,3 \\
\hline & Beneficiários do RGPS, rural (milhöes) & 6,6 & 9,3 & 9,4 & 9,5 & 9,5 \\
\hline & $\begin{array}{l}\text { Valor médio real dos benefícios do } \\
\text { RGPS (dez/2017-INPC) }(\mathrm{R} \$ 1,0)\end{array}$ & 871,9 & $1.161,0$ & $1.124,7$ & $1.185,0$ & $1.269,0$ \\
\hline & $\begin{array}{l}\text { Beneficiários do Regime Próprio de } \\
\text { Previdência Social (RPPS), (milhóes) }\end{array}$ & - & 3,1 & 3,3 & 3,6 & - \\
\hline & $\begin{array}{l}\text { Beneficiários do RPPS, UF e municípios } \\
\text { (milhöes) }\end{array}$ & - & 2,4 & 2,6 & 2,9 & - \\
\hline & Beneficiários do RPPS, União (milhöes) & 0,64 & 0,68 & 0,68 & 0,68 & - \\
\hline \multirow[b]{2}{*}{ Pobreza } & $\begin{array}{l}\text { Benefícios do Programa Bolsa Família } \\
\text { (milhốes de famílias) }\end{array}$ & 6,6 & 14,0 & 13,9 & 13,6 & 13,8 \\
\hline & $\begin{array}{l}\text { Beneficiários do Beneficio de Prestação } \\
\text { Continuada (BPC) e Renda Mensal } \\
\text { Vitalicia (RMV) (milhóes) }\end{array}$ & 2,3 & 4,3 & 4,4 & 4,6 & 4,7 \\
\hline \multirow{7}{*}{ Saúde } & Consultas $\mathrm{p} /$ habitante SUS & 2,43 & $\begin{array}{c}2,83 \\
(2011)\end{array}$ & - & - & - \\
\hline & $\begin{array}{l}\text { Número de cadastramento familiar - Saúde } \\
\text { da Família (milhóes) }\end{array}$ & 22,1 & 32,2 & - & - & \\
\hline & Procedimentos Ambulatoriais (milhóes) & $1.883,5$ & $3.794,2$ & - & - & - \\
\hline & $\begin{array}{l}\text { Atendimentos na Atenção Básica } \\
\text { (milhóes) }\end{array}$ & 868,0 & $1.200,8$ & - & - & - \\
\hline & $\begin{array}{l}\text { Atendimentos na Atenção Especializada } \\
\text { (milhóes) }\end{array}$ & 146,4 & 447,0 & - & - & - \\
\hline & Internaçôes Eletivas (milhôes) & 1,5 & 2,2 & - & - & - \\
\hline & $\begin{array}{l}\text { Cobertura de vacinas imunobiológicas } \\
(\%)\end{array}$ & 76 & 86,1 & - & - & - \\
\hline \multirow{2}{*}{ Educação } & $\begin{array}{l}\text { Matrículas na educação infantil } \\
\text { (milhóes) }\end{array}$ & 4,4 & 5,5 & - & - & 6,1 \\
\hline & $\begin{array}{l}\text { Matrículas no ensino fundamental } \\
\text { regular (milhóes) }\end{array}$ & 30,3 & 19,6 & - & - & 22,8 \\
\hline
\end{tabular}


Tabela 2

Continuação.

\begin{tabular}{|c|c|c|c|c|c|c|}
\hline \multirow{2}{*}{$\begin{array}{l}\text { Dimensóes } \\
\text { e gastos }\end{array}$} & \multirow{2}{*}{ Benefícios e outros } & \multicolumn{5}{|c|}{ Valores } \\
\hline & & 2002 & 2014 & 2015 & 2016 & 2017 \\
\hline \multirow{9}{*}{ Educação } & $\begin{array}{l}\text { Matrículas no ensino fundamental em } \\
\text { tempo integral (milhôes) }\end{array}$ & $\begin{array}{c}1,3 \\
(2010)\end{array}$ & 4,4 & - & - & 3,8 \\
\hline & $\begin{array}{l}\text { Matrículas no ensino médio regular } \\
\text { (milhóes) }\end{array}$ & 7,6 & 7,2 & - & - & 7,9 \\
\hline & $\begin{array}{l}\text { Alimentaçáo escolar - alunos } \\
\text { beneficiados (milhóes) }\end{array}$ & 36,9 & 42,2 & - & - & - \\
\hline & Livros didáticos adquiridos (milhões) & $\begin{array}{c}96 \\
(2005)\end{array}$ & 135,5 & - & - & - \\
\hline & $\begin{array}{l}\text { Caminho da escola - ônibus adquiridos } \\
\text { (mil) }\end{array}$ & $\begin{array}{c}2,4 \\
(2008)\end{array}$ & 4,1 & - & - & - \\
\hline & $\begin{array}{l}\text { Matrículas na educação profissional de } \\
\text { nível médio (milhão) }\end{array}$ & 0,28 & 1,7 & - & - & 1,8 \\
\hline & Matrículas no ensino superior & 1,1 & 2,4 & - & 2,0 & - \\
\hline & Fies - contratos firmados (mil) & $\begin{array}{c}76,1 \\
(2010) \\
\end{array}$ & 732,3 & 287,5 & 203,6 & 175,9 \\
\hline & ProUni - bolsas oferecidas (mil) & $\begin{array}{l}112,3 \\
(2005)\end{array}$ & 306,7 & 329,1 & 329,0 & 361,0 \\
\hline Habitação & $\begin{array}{l}\text { Moradias do Minha Casa Minha Vida } \\
\text { (milhóes) }\end{array}$ & \multicolumn{2}{|c|}{ 2,1 (até 2014) } & 0,4 & 0,7 & \\
\hline \multirow{8}{*}{$\begin{array}{l}\text { Gasto } \\
\text { público }\end{array}$} & $\begin{array}{l}\text { Gasto Público Social Federal - direto } \\
\text { (\% do PIB) }\end{array}$ & 12,60 & 15,20 & 15,70 & - & - \\
\hline & $\begin{array}{l}\text { Gasto Público Social Federal - } \\
\text { tributário (\% do PIB) }\end{array}$ & 0,30 & 1,80 & 1,80 & - & - \\
\hline & Gasto com o RGPS (\% do PIB) & 5,90 & 6,80 & 7,30 & 8,10 & 8,40 \\
\hline & Gasto BPC + RMV (\% do PIB) & 0,33 & 0,66 & 0,70 & - & - \\
\hline & Gasto com abono + seguro desemprego & 0,50 & 0,90 & 0,80 & - & - \\
\hline & $\begin{array}{l}\text { Gasto com educação e cultura (\% } \\
\text { do PIB) }\end{array}$ & 1,60 & 2,30 & 2,40 & - & - \\
\hline & Gasto com saúde (\% do PIB) & 1,65 & 1,65 & 1,64 & - & - \\
\hline & $\begin{array}{l}\text { Gasto do Programa Bolsa Família (\% } \\
\text { do PIB) }\end{array}$ & $\begin{array}{c}0,23 \\
(2004)\end{array}$ & 0,47 & 0,45 & 28,4 & 27,8 \\
\hline
\end{tabular}

ICV: Indice do Custo de Vida; INPC: Índice Nacional de Preços ao Consumidor; BPC: Beneficio de Prestação Continuada; RMV: Renda Mensal Vitalícia; SUS: Sistema Único de Saúde; Fies: Fundo de Financiamento Estudantil; ProUni: Programa Universidade para Todos; PIB: produto interno bruto. Fonte: Ministério do Planejamento, Orçamento e Gestäo (Instituto de Pesquisa Econômica Aplicada e Secretaria de Orçamento Federal) (IPEA, 2016; 2018b; BRASIL, 2017c), Ministério da Economia (Secretaria do Tesouro Nacional, informes da previdência, Anuário Estatístico da Previdência Social) (BRASIL, 2017a; 2017b; 2018), Ministério da Cidades (BRASIL, 2009); Ministério da Educação (INEP, 2018; Fundo Nacional de Desenvolvimento da Educação, 2018), Ministério da Saúde (Relatório Anual de Gestão) (BRASIL, 2017), Departamento Intersindical de Estatística e Estudos Socioeconômicos (2019) e Ministério do Desenvolvimento Social (BRASIL, 2014). 
anos, avançou de 61,7\% em 2002 até chegar em 72,5\% em 2014, apesar de existir número expressivo de brasileiros excluídos da política previdenciária por conta da grande informalidade que domina o mercado de trabalho brasileiro. Já a cobertura da população inativa (mais de 60 anos) esteve estável, em torno de $80 \%$ durante todo o período, demonstrando melhor efetividade do sistema para cobrir as necessidades dessa população. No período, ocorreu permanente ampliação dos benefícios previdenciários, de 18,9 milhóes, em 2002, chegando a 28 milhões em 2014 (ver Tabela 2). Além disso, o valor médio real dos benefícios da previdência também se ampliou em 33\%, derivado em grande parte da valorização real do SM. Os dados apresentados na Tabela 1 mostram que essa política é um elemento importante de garantia de renda e de combate às vulnerabilidades da população idosa.

$\mathrm{Na}$ dimensão da pobreza, houve ampliação da renda dos mais pobres e relevante redução da pobreza e da extrema pobreza. Observa-se, na Tabela 1, que a taxa de pobreza (população vivendo com renda per capita menor que 1/4 do SM), que esteve em patamar elevado durante toda a década de 1990, reduziu sua incidência de $25,7 \%$ da população em 2002 para 8,1\% em 2014, e as demais linhas de pobreza apresentadas na tabela seguiram essa tendência. Esses resultados estão relacionados às políticas de assistência social, que ampliaram e diversificaram os benefícios assistenciais, como mostra a Tabela 2, e ao crescimento econômico que gerou mais emprego e renda.

$\mathrm{Na}$ desigualdade de renda do trabalho, a tendência foi de redução permanente. A Tabela 1 mostra que a participaçáo dos $40 \%$ mais pobres na renda do trabalho se ampliou para 11,4\%, apesar de ser ainda uma participação pequena. $\mathrm{O}$ índice de Gini, que mede o grau de desigualdade na distribuição da renda domiciliar per capita entre os indivíduos, seguiu tendência de contínua queda. A relação 10/40 diminuiu e os mais pobres ampliaram um pouco sua participação na renda, no entanto isso não foi suficiente para mexer na participação do $1 \%$ mais rico na renda $(11,3 \%)$, que continua a deter quase a mesma parcela da renda dos $40 \%$ mais pobres. As políticas sociais e o crescimento econômico, no período, não foram suficientes para efetuar uma mudança mais profunda no elevado padrão de desigualdade brasileira e nas suas consequências negativas para o bem-estar social.

$\mathrm{Na}$ saúde, os dados apresentados na Tabela 1 mostram melhorias na situação de saúde da população; por exemplo, a taxa de mortalidade infantil diminuiu de 35,1 óbitos por mil nascidos vivos em 1995 para 12,4 em 2014. Movimento semelhante ocorreu com a taxa de mortalidade na infância, que diminuiu para 14,9 óbitos por mil nascimentos no ano de 2014. A mortalidade materna, apesar de ter sofrido uma reduçáo, ainda se encontra em patamar bastante elevado. Além disso, houve extensão da esperança de vida ao nascer, que chegou a 75,2 anos em 2014. Essas reduçóes dos valores dos indicadores mostram que a política pública, principalmente o fortalecimento do Sistema Único de Saúde (SUS), com ampliação da atenção primária, sobretudo na modalidade saúde da família, 
entre outros bens e serviços de saúde (ver Tabela 2), protegeu uma parcela mais extensa da população, bem como a protegeu contra conjunto mais diversificado de riscos e agravos.

$\mathrm{Na}$ educação, houve ampliação da escolarização, os indicadores da Tabela 1 mostram que a taxa de frequência da população na faixa etária de 0 a 3 anos se expandiu de 11,7 para 24,6\% entre 2002 e 2014, mas é ainda um acesso reduzido diante das necessidades da população. Para a população de 4 a 14 anos de idade, o acesso à escola foi ampliado. A proporção de analfabetos na população com 15 anos ou mais, apesar da tendência de queda permanente, ainda está em patamar elevado, principalmente por conta das geraçôes mais velhas. O número médio de anos de estudo para a populaçáo com 25 anos ou mais cresceu no período, passando de 6,1 anos para 7,7 anos. Alguns indicadores de progressão dos alunos no sistema mostram avanços no período, mas os patamares atingidos não são bons; por exemplo, a conclusão do ensino fundamental na idade adequada está muito distante do desejável, apenas $74,3 \%$ da população de 16 anos ou mais terminou essa etapa e, no ensino médio, a taxa de frequência líquida foi de 65,7\% em 2014. Os números do Índice de Desenvolvimento da Educação Básica (Ideb) mostram que, apesar do baixo patamar de partida, ocorreu uma pequena, mas constante melhoria da educação. Ver, na Tabela 2, as modificaçóes na matrícula e nos bens e serviços educacionais no período.

No saneamento básico e habitação, ocorreram algumas melhorias e até ampliaçáo da cobertura de serviços dessa dimensão, entretanto não foram suficientes para alterar mais profundamente o quadro de carências. A Tabela 1 mostra que a proporção dos domicílios não servidos por água de rede geral caiu, mas ainda era de 9,0\% em 2014, as diferenças regionais são elevadas, e o serviço de coleta de lixo é ainda pior que o atendimento dos serviços de água. Já a população que não contava com esgotamento sanitário, por rede geral ou fossa séptica, era de $32,4 \%$ em 2014. Além disso, parte do esgoto não é tratada e é jogada na natureza. Os domicílios com adensamento excessivo continuam elevados e ocorreu uma pequena redução no déficit habitacional entre 2007 e 2014, contribuiu para isso a entrega de 2,1 milhóes de moradias no Programa Minha Casa Minha Vida (conferir Tabela 2).

$\mathrm{Na}$ dimensão da segurança pública e violência, os valores dos indicadores, na Tabela 1, mostram uma situação em que a vitimização e a insegurança continuaram altas e crescentes. Os diferentes tipos de homicídios continuaram a crescer, porém em menor velocidade que no período anterior. De acordo com Waiselfisz (2016), os homicídios por armas de fogo (71\% dos homicídios) só não foram maiores em razão da implementação do estatuto e da campanha do desarmamento, iniciados em 2004. O homicídio de homens jovens continuou elevado, atingindo 108,1 por cem mil em 2014, o que significa o extermínio de uma parcela da população masculina jovem, principalmente daquela pobre e negra. 


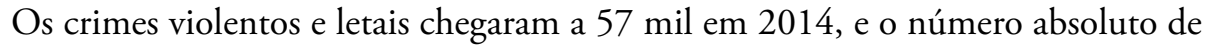
estupros notificados atingiu cerca de $50 \mathrm{mil}$.

A análise das dimensóes demonstra que predominaram, nesse período, alterações nas condições de vida da população, que permitiram o aumento do poder de compra de bens e serviços para a população em idade ativa (inclusão no mundo do trabalho e na renda), para a população na inatividade (inclusão previdência) e para a população mais vulnerável (inclusão assistencial na renda). Houve também a inclusão da maioria da população no acesso a bens e serviços públicos, apesar da permanência dos problemas de qualidade e fragilidades institucionais. Essa alteração positiva nas condiçóes de vida, resultante da maior inclusão social, significou maior bem-estar social para a maioria da população, embora a desigualdade tenha permanecido elevada.

\section{Bem-estar social de 2015-2018: período de retorno da exclusão social}

A estratégia analítica para caracterização do bem-estar social para esse momento é a mesma utilizado na seção anterior, entretanto o período é curto e próximo da atualidade, o que dificulta a obtenção de dados. Por isso, optou-se pela apresentação de dados para cada ano, como é apresentado na Tabela 3. A repetição de dados de 2014 ocorreu pois grande parte dos dados foi proveniente da Pesquisa Nacional por Amostra de Domicílios Contínua (PNAD Contínua) do Instituto Brasileiro de Geografia e Estatística (IBGE), que produz dados aproximados, mas não iguais, ao da Pesquisa Nacional por Amostra de Domicílios (PNAD), do mesmo instituto, e que foram apresentados na Tabela 1.

$\mathrm{Na}$ dimensão do trabalho e renda, o conjunto dos indicadores mostra uma piora expressiva para os trabalhadores e suas famílias neste curto espaço de tempo. A Tabela 3 mostra dados que provam que a desocupação no período ampliou-se fortemente, com a taxa média anual atingindo $12,7 \%$ em 2017, o que corresponde a 13,2 milhóes de pessoas, a maior taxa e o maior contingente dos últimos anos. $\mathrm{O}$ emprego com carteira de trabalho foi o mais penalizado, perdendo 3,3 milhóes de postos. O setor industrial, o mais formalizado, foi um dos que mais perdeu postos de trabalho, 1,5 milhão, seguido pelo setor da construção civil. Além disso, a desocupação atingiu fortemente os mais jovens, chegando a 22,3\% da população de 14 a 29 anos em 2017. Além disso, observa-se que o percentual de subutilização por insuficiência de horas na população ocupada se elevou de 4,9 para 6,6\%, o número de pessoas desalentadas mais que dobrou de tamanho, saindo de 1,5 para 4,2 milhóes, a informalidade cresceu no fim do período, o rendimento médio caiu na maioria do período, assim como a taxa de sindicalização e o SM perdeu centralidade política e valor real. Esses resultados indicam que as dificuldades geradas pela falta de crescimento econômico e pela precarização das 
Tabela 3

Condiçôes de vida: dimensões e painel de indicadores selecionados: 2014-2018.

\begin{tabular}{|c|c|c|c|c|c|c|}
\hline \multirow{2}{*}{ Dimensóes } & \multirow{2}{*}{ Indicadores } & \multicolumn{5}{|c|}{ Valores } \\
\hline & & 2014 & 2015 & 2016 & 2017 & 2018 \\
\hline \multirow{9}{*}{$\begin{array}{l}\text { Trabalho e } \\
\text { renda }\end{array}$} & $\begin{array}{l}\text { Taxa de desocupação na população > } 14 \text { anos } \\
(\%)\end{array}$ & 6,8 & 8,5 & 11,5 & 12,7 & 12,3 \\
\hline & $\begin{array}{l}\text { Taxa de desocupaçáo na população } 14 \text { a } 29 \\
\text { anos }(\%)\end{array}$ & 13,0 & 16,4 & 21,6 & 22,6 & nd \\
\hline & Taxa de desalento na população > 14 anos (\%) & 1,6 & 1,9 & 3,2 & 3,9 & 4,3 \\
\hline & $\begin{array}{l}\text { Rendimento médio real de todos trabalhos, } \\
\text { habitualmente recebidos, população }>14 \\
\text { anos }(\mathrm{R} \$ 1,00)\end{array}$ & 2.228 & 2.222 & 2.180 & 2.230 & 2.243 \\
\hline & $\begin{array}{l}\text { Razão da renda média dos com carteira/renda } \\
\text { média dos sem carteira }\end{array}$ & 0,61 & 0,60 & 0,61 & 0,60 & 0,62 \\
\hline & $\begin{array}{l}\text { Proporção da populaçáo > } 14 \text { anos ocupada } \\
\text { em trabalhos informais (\%) }\end{array}$ & 39,1 & 39,0 & 39,1 & 40,8 & nd \\
\hline & $\begin{array}{l}\text { Empregados com vínculo formal de emprego } \\
\text { (milhôes) }\end{array}$ & 49,6 & 48,1 & 46,1 & nd & nd \\
\hline & $\begin{array}{l}\text { Massa de rendimentos do trabalho principal, } \\
\text { hab. recebido ( } \mathrm{R} \$ \text { bilhôes) }\end{array}$ & 134,2 & 132,2 & 128,4 & 129,8 & 131,9 \\
\hline & $\begin{array}{l}\text { Taxa de sindicalização da população ocupada } \\
(\%)\end{array}$ & 15,9 & 15,8 & 14,9 & 14,4 & nd \\
\hline \multirow{5}{*}{$\begin{array}{l}\text { Previdência } \\
\text { social }\end{array}$} & $\begin{array}{l}\text { População } 16 \text { a } 59 \text { anos ocupada e protegida } \\
(\%)\end{array}$ & 72,5 & 72,5 & 72,2 & 70,9 & nd \\
\hline & População > de 60 anos protegida (\%) & 81,7 & 81,7 & 84,6 & 84,7 & nd \\
\hline & $\begin{array}{l}\text { População > de } 14 \text { anos ocupada/contribuindo } \\
\text { para prev. (milhóes) }\end{array}$ & 59,5 & 59,9 & 59,2 & 58,1 & 58,2 \\
\hline & $\begin{array}{l}\text { População > de } 14 \text { anos ocupada/contribuindo } \\
\text { para prev. (\%) }\end{array}$ & 64,6 & 65,0 & 65,5 & 64,1 & 63,5 \\
\hline & $\begin{array}{l}\text { Populaçáo com renda < } 1 / 2 \text { salário mínimo } \\
\text { (SM) per capita com renda da previdência (\%) }\end{array}$ & 24,2 & 26,2 & 30,5 & 31,3 & nd \\
\hline \multirow{5}{*}{ Pobreza } & População com renda < 1/4 SM per capita (\%) & nd & nd & 12,6 & 13,0 & nd \\
\hline & $\begin{array}{l}\text { População com renda < R\$ } 233 \text { per capita } \\
(\text { Linha FGV) }(\%)\end{array}$ & 8,4 & 10,0 & 10,8 & 11,2 & nd \\
\hline & $\begin{array}{l}\text { População com renda abaixo da linha U\$ } 1,9 \\
\text { PPC per capita }(\%)\end{array}$ & nd & nd & 6,6 & 7,4 & nd \\
\hline & $\begin{array}{l}\text { População com renda abaixo da linha U\$ } 3,2 \\
\text { PPC per capita }(\%)\end{array}$ & nd & nd & 12,8 & 13,3 & nd \\
\hline & $\begin{array}{l}\text { População com renda abaixo da linha U\$ } 5,5 \\
\text { PPC per capita }(\%)\end{array}$ & nd & nd & 25,7 & 26,5 & nd \\
\hline $\begin{array}{l}\text { Desigualdade } \\
\text { de renda }\end{array}$ & Desigualdade de renda, Brasil - Gini & nd & nd & 0,546 & 0,549 & nd \\
\hline
\end{tabular}

Continua... 
Tabela 3

Continuação.

\begin{tabular}{|c|c|c|c|c|c|c|}
\hline \multirow{2}{*}{ Dimensóes } & \multirow{2}{*}{ Indicadores } & \multicolumn{5}{|c|}{ Valores } \\
\hline & & 2014 & 2015 & 2016 & 2017 & 2018 \\
\hline \multirow{6}{*}{$\begin{array}{l}\text { Desigualdade } \\
\text { de renda }\end{array}$} & Desigualdade de renda, Nordeste - Gini & nd & nd & 0,555 & 0,567 & nd \\
\hline & Participação dos 1\% mais rico na renda (\%) & nd & nd & 12,0 & 12,8 & nd \\
\hline & Participaçáo dos $10 \%$ mais rico na renda (\%) & nd & nd & 42,9 & 43,1 & nd \\
\hline & Participaçáo dos $40 \%$ mais pobres na renda (\%) & nd & nd & 12,4 & 12,3 & nd \\
\hline & $\begin{array}{l}\text { Índice de Palma, Brasil (participação dos } \\
10 \% \text { mais ricos/ participação dos } 40 \% \text { mais } \\
\text { pobres) }\end{array}$ & nd & nd & 3,47 & 3,51 & nd \\
\hline & $\begin{array}{l}\text { Razão } 10 / 40 \text { (renda média do } 10 \%+\text { ricos/ } \\
40 \%+\text { pobres) }\end{array}$ & 12,6 & 11,9 & 12,3 & 12,4 & nd \\
\hline \multirow{4}{*}{ Saúde } & $\begin{array}{l}\text { Taxa de Mortalidade Infantil (por mil } \\
\text { Nascidos Vivos) }\end{array}$ & 12,4 & 12,4 & 12,7 & 12,4 & nd \\
\hline & $\begin{array}{l}\text { Taxa de Mortalidade na Infância (por mil } \\
\text { Nascidos Vivos) }\end{array}$ & 14,9 & 14,3 & 14,9 & 14,4 & nd \\
\hline & Razão de mortalidade materna (por 100 mil) & 58,4 & 57,6 & 58,4 & 56,6 & nd \\
\hline & Esperança de Vida ao Nascer (anos) & 75,2 & 75,5 & 75,8 & 76,0 & nd \\
\hline \multirow{10}{*}{ Educação } & Taxa de frequência à escola (0 a 3 anos) (\%) & nd & nd & 30,4 & 32,7 & nd \\
\hline & Taxa de analfabetismo (15 anos ou mais) (\%) & nd & nd & 7,2 & 7,0 & nd \\
\hline & $\begin{array}{l}\text { Número médio de anos de estudos } \\
\text { (populaçáo > } 25 \text { anos) (anos) }\end{array}$ & nd & nd & 8,9 & 9,1 & nd \\
\hline & $\begin{array}{l}\text { População > } 16 \text { anos com o ensindo } \\
\text { fundamental }(\mathrm{EF}) \text { concluído }(\%)\end{array}$ & 73,4 & 74,9 & 74,9 & 75,9 & nd \\
\hline & $\begin{array}{l}\text { Taxa líquida de frequência ao ensino médio } \\
(\mathrm{EM}) \text { ajustada (\%) }\end{array}$ & 67,2 & 68,1 & 69,8 & 70,1 & nd \\
\hline & $\begin{array}{l}\text { População } 15 \text { a } 29 \text { anos, jovem (sem estudar e } \\
\text { sem trabalhar) (\%) }\end{array}$ & 21,3 & 22,6 & 24,2 & 23,5 & nd \\
\hline & $\begin{array}{l}\text { População } 15 \text { a } 29 \text { anos, jovem (sem estudar e } \\
\text { sem trabalhar) (milhóes) }\end{array}$ & 10,3 & 11,0 & 11,7 & 11,9 & nd \\
\hline & Notas no IDEB - EF inicial & $\begin{array}{c}5,2 \\
(2013)\end{array}$ & 5,5 & nd & 5,8 & nd \\
\hline & Notas no IDEB - EF final & $\begin{array}{c}4,2 \\
(2013)\end{array}$ & 4,5 & nd & 4,7 & nd \\
\hline & Notas no IDEB - EM & $\begin{array}{c}3,7 \\
(2013)\end{array}$ & 3,7 & nd & 3,8 & nd \\
\hline $\begin{array}{l}\text { Saneamento } \\
\text { básico e } \\
\text { habitação }\end{array}$ & $\begin{array}{l}\text { Proporção de pessoas em domicílios sem } \\
\text { acesso à coleta de lixo, Brasil (\%) }\end{array}$ & nd & nd & 10,5 & 10,0 & nd \\
\hline
\end{tabular}

Continua... 
Tabela 3

Continuação.

\begin{tabular}{|c|c|c|c|c|c|c|}
\hline \multirow{2}{*}{ Dimensóes } & \multirow{2}{*}{ Indicadores } & \multicolumn{5}{|c|}{ Valores } \\
\hline & & 2014 & 2015 & 2016 & 2017 & 2018 \\
\hline \multirow{5}{*}{$\begin{array}{l}\text { Saneamento } \\
\text { básico e } \\
\text { habitaçấo }\end{array}$} & $\begin{array}{l}\text { Proporção de pessoas em domicílios sem } \\
\text { abastecimento de água, Brasil (\%) }\end{array}$ & nd & nd & 15,1 & 15,1 & nd \\
\hline & $\begin{array}{l}\text { Proporção de pessoas em domicílios sem } \\
\text { abastecimento de água, Norte (\%) }\end{array}$ & nd & nd & 40.3 & 41,2 & nd \\
\hline & $\begin{array}{l}\text { Proporçáo de pessoas em domicílios sem rede } \\
\text { coletora de esgoto, Brasil (\%) }\end{array}$ & nd & nd & 36,3 & 35,9 & nd \\
\hline & $\begin{array}{l}\text { Proporção de pessoas em domicílios sem rede } \\
\text { coletora de esgoto, Nordeste (\%) }\end{array}$ & nd & nd & 57,7 & 56,7 & nd \\
\hline & $\begin{array}{l}\text { Déficit Habitacional relativo aos domicílios } \\
\text { particulares (\%) }\end{array}$ & 9,1 & 9,3 & nd & nd & nd \\
\hline \multirow{6}{*}{$\begin{array}{l}\text { Segurança } \\
\text { pública e } \\
\text { violência }\end{array}$} & Taxa de homicídio (por 100 mil) & 29,8 & 28,9 & 30,3 & nd & nd \\
\hline & $\begin{array}{l}\text { Taxa de homicídio por armas de fogo (por } \\
100 \text { mil) }\end{array}$ & 21,1 & 20,5 & 21,6 & nd & nd \\
\hline & $\begin{array}{l}\text { Taxa de homicídio na populaçáo } 15 \text { a } 29 \\
\text { anos, homens (por } 100 \text { mil) }\end{array}$ & 116,9 & 113,6 & 122,6 & nd & nd \\
\hline & Mortes Violentas Intencionais (MVI) (mil) & 59,7 & 58,5 & 61,6 & 63,9 & nd \\
\hline & $\begin{array}{l}\text { Número absoluto de estupros registrados } \\
\text { (mil) }\end{array}$ & 50,4 & 47,5 & 55,1 & 61,0 & nd \\
\hline & Roubo e furto de veículos (mil) & 513,0 & 514,5 & 557,5 & 544,0 & nd \\
\hline
\end{tabular}

IDEB: Índice de Desenvolvimento da Educação Básica.

Fonte: Instituto de Pesquisa Econômica Aplicada (Ipeadata; 2018a); Instituto Brasileiro de Geografia e Estatística (2017; 2018a; 2018b); Fundação João Pinheiro (2018); Instituto Nacional de Estudos e Pesquisas Educacionais Anisio Teixeira (2018); Ministério da Justiça (fórum)

(BRASIL, 2018; Fundação Getulio Vargas (2018); Fundação Abrinq (2018);

Ministério da Economia (informes previdenciários) (BRASIL, 2018).

relaçôes de trabalho fragilizam a sobrevivência e a proteção social dos trabalhadores e de suas famílias, podendo se agravar, ainda mais com a reforma trabalhista e a terceirização em curso.

$\mathrm{Na}$ dimensão da previdência social, o processo de inclusão previdenciária foi rompido com a redução de contribuintes para o sistema, perda de cerca de 1,4 milhão de contribuintes desde 2014, quando teve início a recessão econômica. A Tabela 3 mostra que 58,1 milhóes de pessoas contribuíram para a previdência (64,1\% dos ocupados) em 2017, o que representa queda de 2,3\% em relação aos 59,5 milhóes de pessoas que haviam contribuído em 2014. Esses dados são evidências de como a recessão econômica e as mudanças no mercado de trabalho tiveram como consequência a ampliação da desproteção social de ampla parcela da população, atingindo também a estabilidade e a segurança no financiamento 
da previdência social. Além disso, o papel dessa política para redução da pobreza diminuiu o que coloca em risco o bem-estar social da população idosa.

$\mathrm{Na}$ dimensão da pobreza, a renda dos mais pobres diminuiu. Com isso, a tendência de redução das situações de pobreza reverteu-se fortemente a partir de 2014 (ver dados na Tabela 3). De acordo com a FGV (2018), desde 2014 até o fim de 2017, cerca de 6,3 milhóes de brasileiros passaram a viver abaixo da pobreza (linha de $\mathrm{R} \$ 233$ per capita), e a pobreza total ampliou-se, atingindo 23,3 milhōes de pessoas. As demais linhas de pobreza adotadas pelo IBGE (2018b) mostram tendência de crescimento da pobreza entre 2016 e 2017. Explicaçôes para esses resultados estáo associados a várias causas, entre elas: a crise econômica, com uma das maiores recessões da história do país; as medidas que facilitaram a precarização das relaçóes de trabalho; as alteraçôes na política de valorização do SM; e o ajuste fiscal (austeridade), que conteve gastos com o Programa Bolsa Família (ver Tabela 2).

$\mathrm{Na}$ dimensão da desigualdade de renda, ocorreu a reversão da tendência de diminuição; a Tabela 3 mostra que o índice de Gini da renda domiciliar per capita entre os indivíduos voltou a ter elevação. Esse índice para o Nordeste é mais elevado que o nacional e teve crescimento mais acelerado, piorando a desigualdade em uma das mais pobres regióes do país. A parcela do 1,0\% com os maiores rendimentos da população ficaram com $12,0 \%$ dos rendimentos em 2016, quase o mesmo que os $40,0 \%$ com os menores rendimentos, $12,4 \%$. A participação do 1 e $10 \%$, superior, na renda ampliou-se, enquanto a dos $40 \%$, inferior, reduziu-se. O Índice de Palma também mostra uma piora na distribuição da renda. A relação 10/40, que havia caído entre 2014 e 2015, voltou a se ampliar nos dois anos seguintes. Não é demais mencionar que a desigualdade brasileira é elevada, como salienta OXFAM (2018), e sua ampliação é péssimo sinal para o bem-estar social dos brasileiros.

$\mathrm{Na}$ dimensão da saúde, a situação da maioria da população, que já era distante da ideal, preocupa ainda mais. Observa-se na Tabela 3 que, no decorrer do período, ocorreu ampliação da taxa de mortalidade infantil entre 2015 e 2016, fato que não havia ocorrido nos últimos 20 anos; o mesmo ocorreu com a mortalidade materna, que já era elevadíssima. Fator preponderante desses resultados foi a política de austeridade fiscal, que enfraqueceu as políticas de saúde e coloca em risco a continuidade do SUS, com o crescimento real dos gastos na área de saúde no período sendo um dos menores dos últimos anos (ver Tabela 2). A aprovação da Emenda Constitucional no 95 (EC-95) em 2016, que congela os gastos públicos durante 20 anos, anula quaisquer possíveis avanços futuros nos serviços públicos de saúde.

Na dimensão da educação a escolarização, mantém-se a inércia de pequenos aumentos, que pouco arranha os problemas estruturais, como as dificuldades com a progressão escolar de parcela expressiva dos alunos, o analfabetis- 
mo - que parece não ter solução —, a baixa escolaridade média da população e as questóes de qualidade. No ensino médio, apesar da taxa líquida de frequência ter evoluído um pouco, o valor atingido é ainda muito baixo diante das expectativas do Plano Nacional de Educação (PNE), e os números do Ideb não são nada animadores (Tabela 3). Além desses problemas, a crise econômica traz consequências profundas para os alunos por causa de fatores externos à escola, tais como a ampliaçáo das dificuldades econômicas das famílias que passam a conviver com desemprego, desalento, queda da renda, aumento da insegurança, entre outros fatores que prejudicam os alunos e os profissionais da educação e que acabam sendo levados para o ambiente escolar. Assim como na saúde, a EC-95 terá efeito devastador sobre os serviços públicos de educação, indispensáveis para a maioria da população.

No saneamento básico e habitação, observam-se movimentos controversos no acesso aos serviços da área. De um lado, o acesso aos serviços de lixo e esgotamento sanitário tiveram pequena ampliação; de outro, o déficit habitacional relativo aos domicílios particulares elevou-se ligeiramente. Já a proporção da população sem serviço de água da rede geral não teve alteração, entretanto a população do Norte piorou sua situação, que já não era boa (ver Tabela 3). Em razão das conexôes transversais da área, essa situação potencializa os problemas de saúde pública, a poluição dos recursos hídricos, entre outros problemas. Esses resultados espelham a desarticulação política e o baixo investimento público e privado na área.

$\mathrm{Na}$ dimensão da segurança pública e violência, a vitimização e insegurança da populaçáo continuam altas e crescentes (Tabela 3). Os diferentes tipos de homicídios, que estavam em patamares elevados no período anterior, continuaram a crescer. O homicídio de homens jovens cresceu cerca de 5\% e atingiu 122,6 por cem mil em 2017. É o extermínio da população jovem/masculina/pobre/negra em marcha forçada. As mortes violentas intencionais chegaram a 63,4 mil em 2017. O número absoluto de estupros notificados atingiu 61 mil. Essa situação relaciona-se à crise econômica, desigualdade, desemprego, fragilidade das políticas de assistência, deficiência no controle do porte de armas, entre outros problemas.

A análise das dimensóes mostrou que, nesse período, ocorreram alteraçôes nas condiçốes de vida da população, que levaram à rápida redução do poder de compra de bens e serviços para a população em idade ativa (exclusão no mundo trabalho e na renda), para a população na inatividade (exclusão da previdência) e para a população mais vulnerável (exclusão assistencial na renda). Conjuga-se a isso a regressão institucional da cidadania e a diminuição da oferta de bens e serviços públicos fundamentais às necessidades sociais da maioria da população. Com isso, a pobreza e a desigualdade voltam a se elevar. Esse rápido retorno ao histórico padrão de exclusão social brasileiro resulta em menor usufruto da renda e riqueza socialmente gerada, cujo significado último é a redução do bem-estar social da maioria da população. 


\section{Considerações finais}

A evolução das condições de vida e o correspondente bem-estar social da população brasileira que foram apresentados revelou um início de século com dois momentos distintos. Um período inicial, mais amplo, de alteraçóes positivas nas condições de vida devido à inclusão social da maioria da população no usufruto da renda e riqueza geradas pela sociedade, com consequente maior bem-estar social. No período seguinte, mais curto, tem-se o retorno da exclusão social, com menor usufruto pela maioria da população da renda e riqueza socialmente geradas e à redução do bem-estar social.

A melhoria do bem-estar com a inclusão social, do momento inicial desse século, representou apenas um arranhão no padrão de exclusão e injustiça social brasileiro, com leve redução de ganhos das classes dominantes sobre o fluxo de renda gerada no período, mas não ameaçando as estruturas patrimoniais e demais interesses vigentes. No momento seguinte, o retorno da exclusão social é resultante da retomada do pleno controle do poder político pelas classes dominantes, que voltam a realizar plenamente seu ideário de espoliação do país, pouco se importando com o que isso significa em termos de bem-estar social para a populaçáo brasileira.

\section{Referências}

BRASIL. Emenda Constitucional no 95 (EC-95), de 15 de dezembro de 2016. 2016. Disponível em: <http://www.planalto.gov.br/ccivil 03/constituicao/Emendas/Emc/ emc95.htm >. Acesso em: jan. 2019.

BRASIL. Ministério da Fazenda. Secretaria de Previdência. Anuário Estatístico da Previdência Social - Suplemento Previdência do Servidor Público - AEPS 2017. Brasília: Ministério da Fazenda, 2017a. v. 1.

BRASIL. Ministério da Fazenda. Secretaria de Previdência. Empresa de Tecnologia e Informaçóes da Previdência. Anuário Estatístico da Previdência Social - AEPS 2017. Brasília: Ministério da Fazenda, 2017b. v. 24.

BRASIL. Ministério da Fazenda. Secretaria de Previdência. Informe da Previdência Social, Brasília, v. 30, n. 1, jan. 2018.

BRASIL. Ministério das Cidades. Déficit habitacional no Brasil 2007. Brasília: Ministério das Cidades, 2009.

BRASIL. Ministério do Planejamento, Desenvolvimento e Gestão. Boletim Estatístico de Pessoal e Informaçóes Organizacionais, Brasília, v. 21, n. 249, jan. 2017c.

DEPARTAMENTO INTERSINDICAL DE ESTATÍSTICA E ESTUDOS SOCIOECONÔMICOS (DIEESE). Salário mínimo de 2019 é fixado em R\$ 998,00. Nota Técnica, São Paulo, n. 201, jan. 2019. 
INSTITUTO BRASILEIRO DE GEOGRAFIA E ESTATÍSTICA (IBGE). Síntese de indicadores sociais: uma análise das condições de vida da população brasileira - 2017 . Rio de Janeiro: IBGE, 2017.

INSTITUTO BRASILEIRO DE GEOGRAFIA E ESTATISTICA (IBGE). PNAD continua retrospectiva 2012-2018. Rio de Janeiro: IBGE, 2018a.

INSTITUTO BRASILEIRO DE GEOGRAFIA E ESTATISTICA (IBGE). Síntese de indicadores sociais: uma análise das condiçôes de vida da população brasileira - 2018 . Rio de Janeiro: IBGE, 2018b.

INSTITUTO DE PESQUISA ECONÔMICA APLICADA (IPEA). Atlas da violência 2018. Rio de Janeiro: IPEA, 2018a.

INSTITUTO DE PESQUISA ECONÔMICA APLICADA (IPEA). Ipeadata 3.0. Brasília. Disponível em: <http://ipeadata.gov.br/beta3/>. Acesso em: 10 dez. 2018.

INSTITUTO DE PESQUISA ECONÔMICA APLICADA (IPEA). Políticas sociais: acompanhamento e análise. Boletim de Políticas Sociais, Brasília, n. 25, 2018b.

INSTITUTO DE PESQUISA ECONÔMICA APLICADA (IPEA). Retrato das desigualdades de gênero e raça. 5. ed. Brasília: IPEA, 2016.

INSTITUTO NACIONAL DE ESTUDOS E PESQUISAS EDUCACIONAIS ANÍSIO TEIXEIRA (INEP). Relatório do $2^{\circ}$ Ciclo de Monitoramento das Metas do Plano Nacional de Educaçáo - 2018. Brasília: INEP, 2018.

FUNDAÇÃO ABRINQ. Observatório da criança e do adolescente. Sáo Paulo: Fundação Abrinq. Disponível em: <https://observatoriocrianca.org.br/cenario-infancia $>$. Acesso em: 20 nov. 2018.

FUNDAÇÃO GETULIO VARGAS (FGV). Qual foi o impacto da crise sobre a pobreza e a distribuiçáo de renda? Rio de Janeiro: FGV, 2018.

FUNDAÇÃO JOÃO PINHEIRO (FJP). Déficit habitacional no Brasil 2015. Belo Horizonte: FJP, 2018.

OXFAM BRASIL (OXFAM). País estagnado - um retrato das desigualdades brasileiras. Brasília: OXFAM. Disponível em: <https://oxfam.org.br/um-retrato-das-desigualdadesbrasileiras/pais-estagnado/>. Acesso em: nov. 2018.

RIPSA. Indicadores básicos para a saúde no Brasil: conceitos e aplicaçóes. 2. ed. Brasília: Organização Pan-Americana da Saúde, 2013. Disponível em: http://www.ripsa.org.br/ vhl/indicadores-e-dados-basicos-para-a-saude-no-brasil-idb/base-de-dados-idb/. Acesso em: dez. 2018.

WAISELFISZ, J.J. Mapa da Violência 2016: Homicídios por armas de fogo no Brasil. Rio de Janeiro: FLACSO/Brasil, 2016. 


\section{SOBRE O AUTOR}

Jorge Abrahấo de Castro é doutor em Economia pelo Instituto de Economia (IE-Unicamp) e membro da Associação Brasileira de Economistas pela Democracia (ABED). Foi diretor da Diretoria de Estudos e Políticas Sociais do Instituto de Pesquisa Econômica Aplicada (IPEA) e diretor do Departamento de Temas Sociais da Secretaria de Planejamento e Investimento do Ministério do Planejamento. Pesquisador/professor associado da Universidade de Brasília (UnB) e professor do Departamento de Economia da Universidade Católica de Brasília (UCB).

Recebido em 2 de abril de 2019.

Aceito em 6 de setembro de 2019. 